\title{
EXPLORANDO UM MUSEU DE PRÉ-HISTÓRIA COMO ESPAÇO NÃO FORMAL PARA O ENSINO E APRENDIZAGEM DE CIÊNCIAS
}

\author{
EXPLORING A MUSEUM OF PREHISTORY AS A NON-FORMAL SPACE FOR \\ TEACHING AND LEARNING SCIENCE
}

DOI: http://dx.doi.org/10.23926/RPD.2526-2149.2018.v3.n2.p461-476.id188

\section{Edimarcio Francisco da Rocha \\ Doutor em Educação em \\ Ciências e Matemática \\ (REAMEC/UFMT). \\ Professor EBTT (IFMT). \\ edimarcio.rocha@roo.ifmt.e \\ du.br}

\section{Eduardo Ribeiro Mueller}

Doutor em Educação em Ciências e Matemática

(REAMEC/UFMT).

Professor na Universidade

Federal de Mato Grosso

(UFMT).

edurmuller@hotmail.com

\section{Edslei Rodrigues de Almeida}

Doutor em Educação em

Ciências e Matemática

(REAMEC/UFMT).

Professor EBTT (IFRO).

edslei.rodrigues@ifro.edu.br

\begin{abstract}
Resumo: Neste artigo, apresentamos uma experiência sobre a utilização de espaços não formais para o desenvolvimento de atividades relacionadas ao ensino e à aprendizagem de conteúdos curriculares que podem envolver diversas áreas do conhecimento, como a química e a biologia. Desse modo, destacamos um museu de pré-história como um potencial espaço não formal para o desenvolvimento dessas atividades. Utilizando pressupostos da pesquisa qualitativa e como recurso metodológico a aula de campo, realizamos observações e proposições sobre possíveis abordagens de temas relacionados ao ensino e aprendizagem de conceitos científicos, tendo como objetivo indicar aos professores meios alternativos ao processo tradicional de ensino que fragmenta o conhecimento. Como um espaço não formal para o ensino, o museu apresenta elementos que podem contribuir para a aprendizagem, uma vez que oferece formas de contextualizar o conhecimento das diferentes áreas, demonstrando ser um ambiente que propicia trabalhar assuntos relacionados com as Ciências da Natureza e, também, a conceitos étnicos, históricos, geográficos, linguísticos e políticos. Além disso, esse espaço se caracteriza como um local capaz de romper as barreiras da sala de aula, permitindo a interação do indivíduo com os artefatos expostos, contextualizando questões locais e contribuindo para a apropriação do conhecimento científico de maneira construtivista.

Palavras-chave: Museu. Alfabetização científica. Mediação. Construtivista
\end{abstract}

\begin{abstract}
In this article, we present an experience about the use of nonformal spaces for the development of activities related to the teaching and learning of curricular contents that may involve several areas of knowledge, such as chemistry and biology. Thus, we highlight a pre-history museum as a potential non-formal space for the development of these activities. Using qualitative research assumptions and as a methodological resource the field class, we make observations and propositions about possible approaches to topics related to teaching and learning of scientific concepts, aiming to indicate to teachers alternative means to the traditional teaching process that fragments knowledge. As a non-formal space for teaching, the museum presents elements that can contribute to learning, since it offers ways to contextualize the knowledge of the different areas, proving to be an environment that facilitates work related to Nature Sciences and, also, to ethnic, historical, geographical, linguistic and political concepts. In addition, this space is characterized as a place capable of breaking the barriers of the classroom, allowing the interaction of the individual with the exposed artifacts, contextualizing local issues and contributing to the appropriation of scientific knowledge in a constructivist way.

Keywords: Museum. Scientific Literacy. Mediation; Constructivist.
\end{abstract}




\section{INTRODUÇÃO}

A utilização de espaços não formais para o desenvolvimento e realização de aulas constitui-se um recurso didático importante e facilitador do aprendizado. No entanto, apesar dos benefícios, é comum que professores optem pelo espaço escolar como ambiente exclusivo para a prática educativa (JACOBUCCI, 2008). Isso ocorre devido a diferentes causas, entre as quais destacamos possíveis falhas na formação inicial docente, que não incentiva a exploração de alternativas para os métodos tradicionais, que engendraram a escola como instituição formal, responsável pela formação intelectual dos estudantes, ou ainda como formadora de mão de obra doutrinada, sob o dogma de que só se aprende tendo o professor para ensinar em um 'ambiente' controlado, a sala de aula (OVIGLI, 2011).

Estratégias que rompam com essa barreira, promovendo a interação com outros ambientes que permitam ao aluno perceber e entender que o conhecimento científico não é algo isolado e desconectado da natureza, são premissas primordiais para os processos de alfabetização científica que, segundo Chassot (2003) requerem que o sujeito seja capaz de ler e interpretar fenômenos naturais com o auxílio da ciência. Para o referido autor, a ciência é uma linguagem utilizada para esse fim.

A experiência que propomos neste trabalho objetiva proporcionar a professores meios que possibilitem novos olhares sobre metodologias para o ensino de ciências e que promovam momentos pedagógicos capazes de envolver diversas áreas do conhecimento em um mesmo espaço $^{1}$, que podem ser, por exemplo, um museu, um parque, um zoológico ou até mesmo um aterro sanitário. Em nosso entendimento, ensinar e aprender ciências não é algo exclusivo da formalidade da sala de aula, pois outros locais podem ser explorados como espaços não formais, caso do museu apresentado neste trabalho. Esses espaços, "estabelecem uma relação própria com o conhecimento científico, no entanto, em todos há algum nível de tradução ou transposição deste saber (MARANDINO, 2005, p. 178).

Entre as várias possibilidades que existem, escolhemos o museu de Pré-História Casa Dom Aquino, na cidade de Cuiabá/MT, por entendermos que esse local se caracteriza como um espaço não formal, no qual podemos trabalhar assuntos do currículo escolar, através da observação e do estudo dos objetos concretos que estão em exposição, numa perspectiva Vygotskiana, possibilitando a mediação entre o objeto e o pensamento abstrato necessários para a construção do conhecimento (MUELLER, 2012).

\footnotetext{
${ }^{1}$ Desde que seja planejado com antecedência, tendo um roteiro e objetivos definidos, caso contrário, se tornam apenas espaços para visitas ou passeios.
} 
Para o desenvolvimento deste trabalho, ancoramos em uma abordagem qualitativa, utilizando como recurso metodológico a aula de campo, como estratégia de trabalho em relação ao museu, considerando-o um espaço não formal para o ensino e a aprendizagem de ciências, tendo como objetivo indicar meios alternativos ao processo tradicional de ensino que fragmenta o conhecimento.

\section{REFERENCIAL TEÓRICO}

O ensino de ciências, quer seja a química, a física ou a biologia, desenvolveu-se engessado no método científico, positivista, que resultou na fragmentação do conhecimento e que, na maioria das escolas, restringe-se ao ambiente formal da sala de aula. Nesse sentido, é necessário transgredir esse sistema positivista disciplinar e promover ações em "busca de uma alfabetização científica ou de uma educação nas ciências” (CHASSOT, 2016, p. 202) e, uma possível maneira para tal, é a exploração de espaços não formais para a ação de ensinar e promover a aprendizagem de modo interdisciplinar.

Para Jacobucci (2008), os museus se enquadram nesse contexto. Conforme a autora, os museus constituem-se como um ambiente potencial para a apropriação da cultura científica. Essa característica ultrapassa as fronteiras da sala de aula e demonstra uma evolução no processo de ensinar, firmando-se inter/multidisciplinarmente, pois possibilita trabalhar conteúdos diversos relacionados à Física, Química, Matemática, História, Geografia, entre outros.

A interdisciplinaridade, de acordo com Fazenda (2008), é uma busca constante por respostas a uma pergunta e isso se dá pela pesquisa. É algo que precisa ser vivenciado, exercido, uma filosofia de interiorização do conhecimento. Logo, entendemos o museu como um espaço que pode proporcionar trabalhos interdisciplinares que resultem na interiorização dos conceitos a serem explorados nesse local. Entretanto, para utilizar esse espaço, o professor precisa pesquisá-lo e compreendê-lo, para posterior utilização do mesmo, além de conhecer o perfil dos alunos para adequação de seu planejamento de aula.

Marandino (2011) aponta em seu estudo que a prática educativa referente à aprendizagem desenvolvida em museus pode assumir duas abordagens, sendo uma positivista, na qual o visitante na condição de aprendiz é um mero espectador e outra construtivista, na qual o museu é tido como um ambiente social em que o aprendiz interage com ele e o conhecimento é construído a partir dessa interação. Tais abordagens serão praticadas conforme a compreensão 
do professor sobre o que é um espaço não formal e sua competência epistemológica no que se refere à aprendizagem.

Em muitas situações, os espaços não formais são entendidos como locais que negam a escola formal. São espaços que permitem maior difusão do que se propõe a ensinar e aprender, não seguindo hierarquias como nos espaços formais (GADOTTI, 2005).

Vieira, Bianconi e Dias (2005) entendem que, ao longo da vida, as pessoas podem aprender tanto em ambientes formais, como também em espaços não formais como museus, centros de ciências e zoológicos. Nesses espaços é proporcionada a aprendizagem de conteúdos vindos da escola formal, desde que as aulas sejam desenvolvidas de forma direcionada e com objetivo definido.

O conceito de espaços não formais para fins educativos ainda é motivo de discussão entre os pesquisadores, devido a definição do que pode ser utilizado como tal, podendo levar a conclusão de que espaço formal é o ambiente escolar. Assim, fora desse ambiente inserem-se os espaços não formais, o que, de acordo com Jacobucci (2008), pode ser confundido como informalidade ou descaso. Entretanto, a autora aponta que os espaços não formais são aqueles em que podem ocorrer a prática educativa dentro de um planejamento, evitando que as aulas nesses espaços não se concretizem apenas como passeios ou visitas.

Segundo Marandino (2011), não há consenso na conceituação desses espaços. Os pares não utilizam a mesma linguagem, dificultando a compreensão do que sejam os espaços formais e não formais e, até mesmo, a delimitação desses espaços.

Ainda há a categorização dos espaços não formais como Institucionais e não Institucionais, sendo os primeiros, espaços regulamentados que possuem uma equipe técnica responsável pelas atividades, como Museus, Zoológicos, Jardins Botânicos, Planetários, Centros de Pesquisa, entre outros. Já os não institucionais são praças, ruas, cinemas, praias, entre outros (JACOBUCCI, 2008).

Nesta concepção, apontamos o museu de Pré-História Casa Dom Aquino como um espaço não formal institucionalizado, sendo propício para a prática pedagógica, mesmo não sendo concebido para esse fim, conforme descreve Jacobucci (2008) e Queiroz, et al (2011). Já Marandino (2011, p. 109) entende que "as exposições de museus são também unidades pedagógicas nas quais processos de recontextualização do discurso científico irão ocorrer".

Outro aspecto a ser observado é o modo como a concepção de espaços não formais de aprendizagem são trabalhados nos cursos de formação de professores. Ovigli (2011) afirma que deve ser incluído, na formação de professores, um aprofundamento teórico sobre possibilidades 
da exploração dos espaços não formais, uma vez que, geralmente, eles desconhecem as especificidades desses ambientes. $\mathrm{O}$ autor ressalta que os museus se constituem como um local de atuação para futuros professores e que esses espaços vêm ganhando destaque na educação científica.

\subsection{O MUSEU COMO ESPAÇO DE INTERAÇÃO PARA A MEDIAÇÃO DA APRENDIZAGEM}

O museu se constitui como um espaço capaz de mediar a construção do conhecimento científico. Considerando a mediação como um conceito da teoria sócio interacionista de Lev Vygotsky, três questões são determinantes na análise que se faz dela:

(1) Qual a relação entre os seres humanos e o seu ambiente físico e social? (2) quais as formas novas de atividade que fizeram com que o trabalho fosse o meio fundamental de relacionamento entre o homem e a natureza e quais são as consequências psicológicas dessas formas de atividade? (3) qual a natureza das relações entre o uso de instrumentos e o desenvolvimento da linguagem? (VYGOTSKY, 1998, p. 25)

Colocaremos a primeira questão como central em nossa fundamentação. Ao questionar a relação entre os seres humanos e o seu ambiente físico e social, Vygotsky nos chama atenção para a importância dessa relação no processo de aprendizado e desenvolvimento do sujeito que se relaciona. Nesse sentido, estabelecer relações com ambientes diversos potencializa o aprendizado e o desenvolvimento, já que, na concepção Vygotskiana, melhor se desenvolve quem melhor aprende. $\mathrm{O}$ museu a que nos referimos pode ser considerado como um elemento interposto na relação entre o sujeito que o visita/conhece e aquilo que ele pode aprender nesse ambiente, proveniente de sua interação, tornando-se um lugar capaz de mediar a aprendizagem, além de proporcionar ao sujeito, como espaço não formal de aprendizagem, o desenvolvimento de suas funções psicológicas superiores.

A abordagem da psicologia como ciência mental por Vygotsky descreve as propriedades dos processos psicológicos superiores como aqueles que caracterizam o funcionamento psicológico tipicamente humano, com ações conscientemente controladas, atenção voluntária, memorização ativa, pensamento abstrato e comportamento intencional, nos diferenciando dos demais animais, que possuem apenas mecanismos mais elementares, como reflexos, reações automáticas e associações simples (MUELLER, 2012).

O espaço investigado nos estimula a imaginar situações passadas, subordinadas ao aprendizado dos conceitos intrínsecos ao conhecimento lá presente e requer, portanto, a utilização do pensamento abstrato, ação que, segundo Vygotsky (1998), só pode ser exercida por seres humanos, únicos capazes de funções psicológicas dessa natureza. 


\section{Metodologia}

No que concerne à metodologia, este trabalho está ancorado no âmbito da pesquisa qualitativa, realizada no campo da educação formal e não formal. Neste caso, buscamos explorar e apontar as possibilidades da produção de conhecimento nos museus, utilizando como recurso metodológico a aula de campo, investigando o potencial desse ambiente para o ensino não formal e interdisciplinar, a fim de se propor meios alternativos para o ensino de ciências que rompam com o modelo positivista-tradicional comumente engendrado nas escolas.

Segundo Minayo (1994), na investigação qualitativa, o trabalho é desenvolvido considerando significados, motivações, valores e atitudes que correspondem a um espaço mais profundo das relações, dos processos e dos fenômenos inerentes à pesquisa de campo. Essa abordagem metodológica se adequa, ainda conforme a autora, ao estudo de crenças, de representações e dos produtos e objetos advindos do devir humano ao longo de sua história.

Em relação às pesquisas que envolvem museus, vários são os investigadores que buscam compreender sua dimensão educacional, como espaços de construção do conhecimento e/ou transposição didática/museográfica e/ou recontextualização do discurso pedagógico, dentre eles, Cazzeli et al. (1999); Marandino (2001); Gouvêa, Marandino e Leal (2003); Cazelli, Marandino e Studart (2003); Marandino (2005); Martins (2006); Figueroa e Marandino (2014); Tempesta e Gomes (2017). Observamos que, dentre os autores mencionados, alguns realizaram pesquisas para identificar as tendências pedagógicas presentes nas atividades realizadas nestes espaços educacionais.

Quanto à aula de campo, neste trabalho a inserimos como um recurso metodológico e destacamos outros trabalhos que a utilizaram neste mesmo viés, a saber: Seniciato e Cavassan (2004); Dourado (2006a); Dourado (2006b); Almeida e Silva (2010); todos destacaram a importância da aula de campo realizada em ambientes naturais ou em espaços não formais, como uma metodologia eficiente, tanto para envolver os alunos, quanto para definir temáticas de pesquisa, dependendo do nível em que esta será realizada. Há também a ênfase na aula de campo como um instrumento de superação da fragmentação do conhecimento (SENICIATO e CAVASSAN, 2004).

Assim, para alcançarmos o objetivo de realizarmos nossa pesquisa a partir de problemas que identificamos no cotidiano docente, como a abstração de conceitos ou as dificuldades de compreender um assunto sob o olhar de múltiplas áreas, fizemos uma visita ao museu de Préhistória Casa Dom Aquino, para conhecer e avaliar a potencialidade do ambiente para possíveis aulas relacionadas ao ensino de ciências e matemática em ambientes não formais. Foram 
realizadas observações, anotações de campo, e registros fotográficos que nos auxiliaram no processo reflexivo que culminou na elaboração de propostas temáticas que podem nortear o desenvolvimento de aulas futuras e incentivar a prática docente para além da sala de aula. Defendemos que esse espaço permite estabelecer relações entre os objetos que se encontram expostos e o currículo escolar.

\subsection{DESCRIÇÃO DO MUSEU ESTUDADO ${ }^{2}$}

A busca por meios que inovem a prática docente no que se diz respeito a atividade aula, principalmente por parte dos professores das áreas de ciências da natureza, leva-nos à apresentação do museu de Pré-história Casa Dom Aquino ${ }^{3}$ como um espaço que permite empreender diversos conteúdos referentes a nossa região e que pertencem à diversas áreas do conhecimento.

O museu de Pré-história Casa Dom Aquino foi inaugurado em dezembro de 2006 e fica localizado na avenida Beira Rio, bairro jardim Europa, na cidade de Cuiabá. Recebeu esse nome em virtude de um ilustre morador, Dom Francisco de Aquino Correa, nascido em 1885 e que residiu no local. Entre outros cargos, ele foi presidente da província de Mato Grosso no início do século XX. Além de Dom Aquino, também nasceu nessa casa, em 1848, Joaquim Murtinho, médico que ajudou a introduzir a homeopatia no Brasil. Como empresário, atuou no segmento de erva mate e, como político, teve grande influência regional e nacional, ocupando diversos cargos importantes, entre os quais, senador e ministro da fazenda.

Em relação à construção da casa, que foi erguida pela família de Joaquim Murtinho no século XIX, é possível explorar aspectos geográficos e o contexto histórico em que ela foi construída, já que se trata de uma edificação às margens do Rio Cuiabá, o que contribuía para as atividades comerciais, pois o rio era a principal via para deslocamento de mercadorias naquela época. Uma outra característica da edificação é a espessura das paredes, muito mais largas do que as temos habitualmente hoje, técnica que demonstrava preocupação com o conforto térmico, uma vez que a região possui clima tropical, com temperaturas podendo passar dos $40^{\circ} \mathrm{C}$ em boa parte do ano.

Transformada em museu, a casa apresenta peças de fósseis e artefatos que foram encontrados na região do Estado de Mato Grosso, além de materiais iconográficos que

\footnotetext{
${ }^{2}$ Fonte: http://www.cultura.mt.gov.br/-/2675771-museu-de-pre-historia e http://www.camaracba.mt.gov.br/index.php?pag=tur_item\&id=34. Acesso em 10 de março de 2017.

${ }^{3}$ Durante a elaboração deste texto, o referido museu passou por modificações em seu nome, entretanto, optamos em manter o nome original referente ao período da pesquisa de campo.
} 
permitem trabalhar conteúdos relacionados à evolução do planeta em aspectos que contemplam múltiplos componentes curriculares e, assim, possibilitar o desenvolvimento de práticas educativas envolvendo professores de disciplinas diversas, ampliando aspectos pedagógicos referentes aos processos de ensino e aprendizagem quando comparados ao que ocorre no espaço formal da escola.

\section{Resultados}

O espaço pesquisado oferece diferentes possibilidades para o desenvolvimento de aulas, proporcionando momentos de interação com um material rico em informações e que permite a apropriação da cultura científica. Esses materiais podem ser compreendidos como facilitadores do exercício, instrumentos ou signos que atuam como mediadores na construção do conhecimento, sobretudo do passado, o qual nos requisita operações mentais no campo abstrato (VYGOTSKY, 1998) e que, conforme Marandino (2011), promovem a aprendizagem construtivista. Na sequência, apresentamos alguns exemplos do que pode ser explorado no museu, bem como possíveis relações curriculares.

Nossa primeira observação, foi uma linha do tempo (figura 1), na qual destacamos como central o conceito de evolução.

Figura 1 - Eras geológicas.

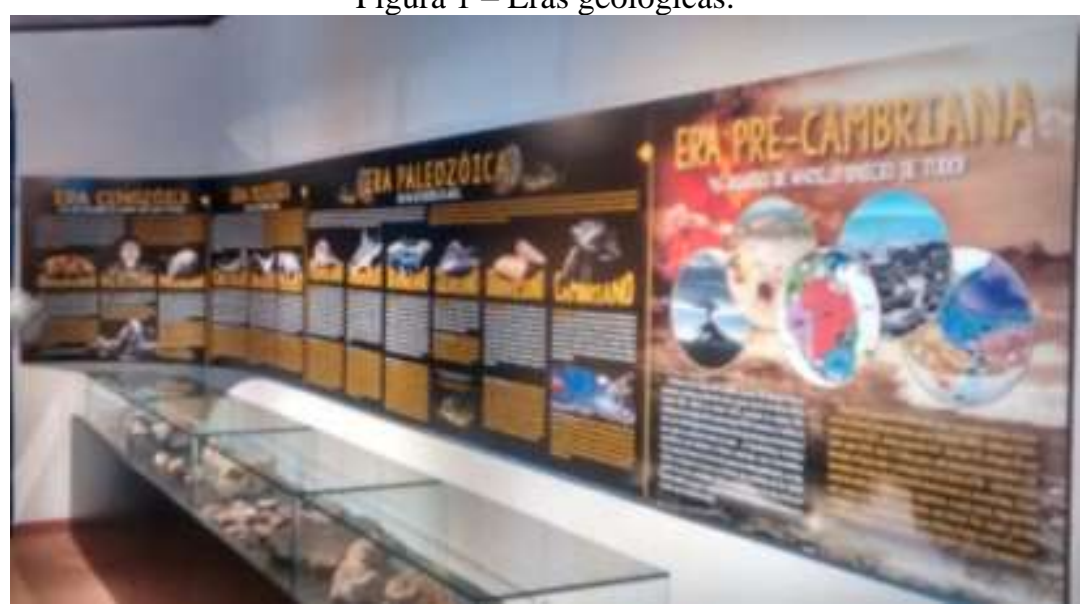

Foto: Acervo dos autores.

As eras geológicas podem ser observadas numa sequência onde aparecem: Era précambriana (4,6 bilhões de anos), era Paleozóica (550-250 milhões de anos), era Mesozóica (251-65 milhões de anos) e era Cenozóica (65 milhões de anos aos dias atuais).

Dentre as possibilidades de estudo acerca das eras, destacamos a evolução geológica do planeta terra (resfriamento e formações rochosas) e das diferentes espécies de animais, as quais podem servir de objeto de estudo da geologia (em Geografia) e Biologia. A concepção de tempo 
pode ser problematizada pela matemática nesse contexto; a Química pode trabalhar a formação dos gases atmosféricos e da água e seus ciclos (gases e água), e a Física, os fenômenos da natureza inerentes a essas transformações climáticas, como o próprio resfriamento, deslocamento de massas de ar, umidade relativa, formação de tempestades e descargas elétricas.

Destacamos que deve ser entendido que, ao propormos a abordagem que descrevemos no parágrafo anterior, precisamos ter a clareza de que muitas vezes (ou quase sempre) os conteúdos das diferentes áreas não são ensinados em paralelo devido ao modelo disciplinar que impera em nossas escolas, característica essa que dificulta um trabalho interdisciplinar. Chassot (2003, p. 92) defende que devemos criar "condições para uma prática escolar [...] dentro de uma perspectiva interdisciplinar e contextualizada" como meio de combater a fragmentação do ensino tradicional.

O fenômeno deve ser o eixo central para o desenvolvimento dos demais conceitos. Devemos pensar em propostas de ensino que utilizem o fenômeno como gerador de estudos e discussões, articulando as áreas de conhecimento para a construção de conceitos que levem à compreensão do que está sendo estudado para além da fragmentação das ciências. Essa linha de raciocínio é empregada para as demais observações que se seguem.

Defronte da linha que representa as eras geológicas, encontra-se um balcão com peças referentes à cada era (figura 2) e que apresenta dois estromatólitos encontrados na região de Cáceres/MT. Esses materiais são depósitos de calcário datados do período pré-cambriano, originados a partir da ação de cianobactérias que são fotossintetizantes.

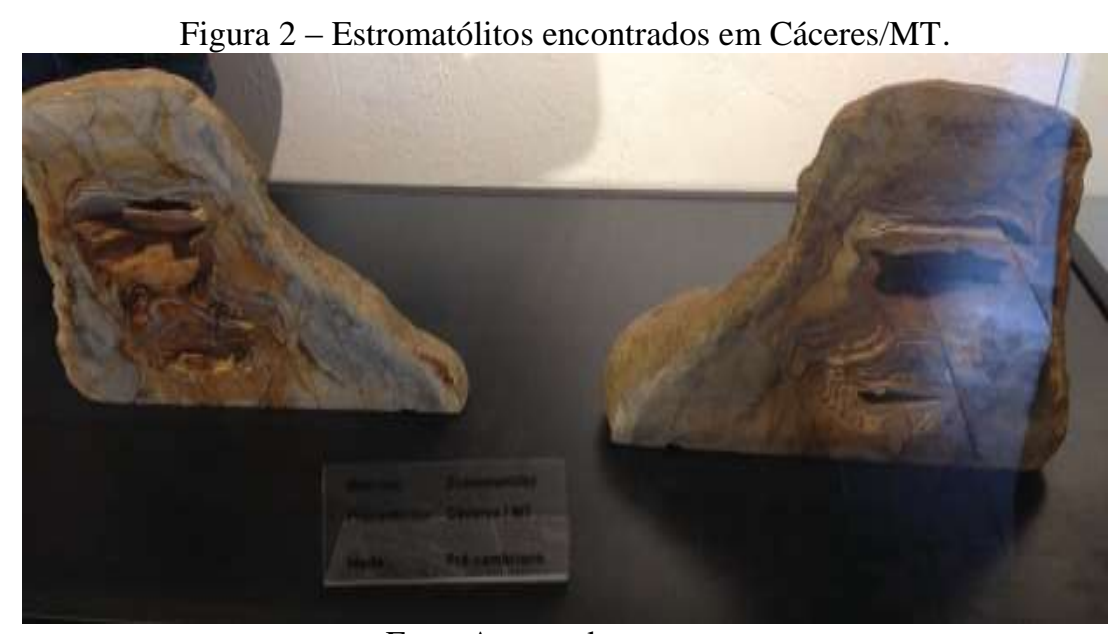

Foto: Acervo dos autores.

Por meio dessas peças é possível abordar conceitos do universo de estudo da Biologia e Química, contextualizando o assunto fotossíntese como fenômeno que ocorre não somente em plantas, desconstruindo um conceito muitas vezes 'ensinado e aprendido' como tal, ou ainda 
trabalhar com o conteúdo relacionado ao componente curricular Geografia, que aborda conceitos sobre a constituição do planeta e das rochas, por exemplo.

Além dessas peças, o museu possui outras que foram encontradas nas regiões de Chapada dos Guimarães e Barra do Garças, ambas cidades do estado de Mato Grosso, que remetem à era Paleozóica. Essas peças ilustram e contextualizam a região dentro de um cenário global muitas vezes apresentado nos livros como algo distante da realidade local.

O processo de fossilização pode servir de objeto de estudo no tocante ao processo de conservação de seres vivos pré-históricos, utilizado pela paleontologia no desvendamento evolutivo de espécies animais e vegetais. As datações utilizando Carbono 14 foram fundamentais para a construção da linha de evolução do planeta e é um tema que pode ser abordado tanto na perspectiva da Química quanto da Física, trazendo a discussão de conteúdos relativos a isótopos e radioatividade.

A linha do tempo também retrata os povos indígenas localizados no estado de Mato Grosso e suas respectivas línguas (figura 3). O texto explicativo assinala que, das 180 línguas indígenas existentes no Brasil, cerca de 140 são encontradas na região da Amazônia Legal, das quais 45 são faladas no Estado de Mato Grosso.

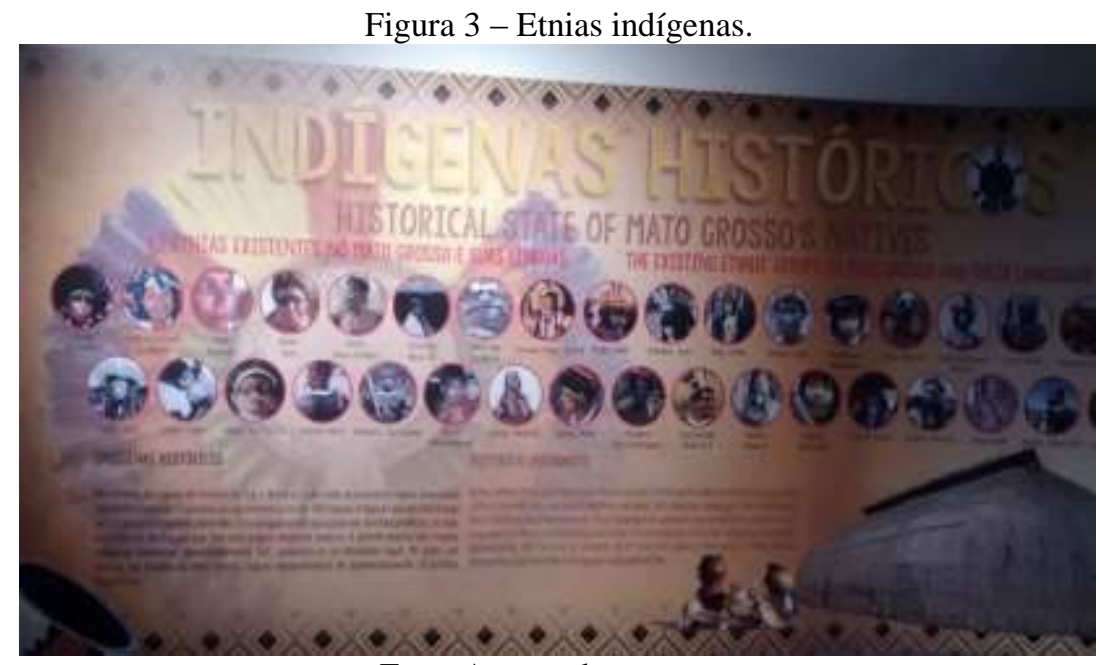

Foto: Acervo dos autores.

Este seria um excelente objeto de estudo da língua portuguesa, literatura mato-grossense e influências desses povos na cultura local e ainda permitiria trazer para a discussão questões sobre etnoconhecimento.

Segundo Sabbatini (2003), os museus são instituições capazes de proporcionar experiências para a compreensão de princípios científicos e tecnológicos. Nesse âmbito, esse espaço apresenta a exposição de diferentes tipos de fragmentos de rochas e artefatos referentes ao homem pré-histórico (figura 4). 
Figura 4 - Artefatos do homem pré-histórico.

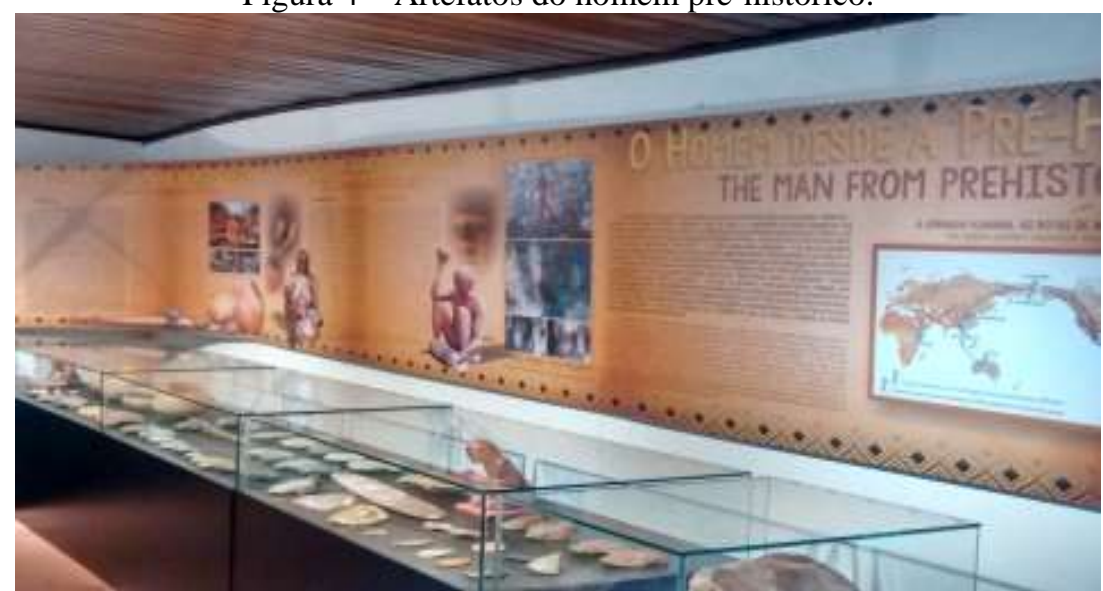

Foto: Acervo dos autores.

Algumas peças são artefatos de civilizações que povoaram a região mato-grossense há aproximadamente 10 mil anos (informações verificadas no próprio museu). Os artefatos podem ser objetos para o estudo do conceito de tecnologia, uma vez que serviram para facilitar ações humanas em épocas pré-históricas, tais como cortar carne e couro de animais, possibilitando realizar a contextualização da evolução tecnológica para os dias atuais.

Também é possível explorar questões relacionadas à extinção de espécies de animais a partir de uma réplica (figura 5) da estrutura esquelética do dinossauro Tiranossauro Rex.

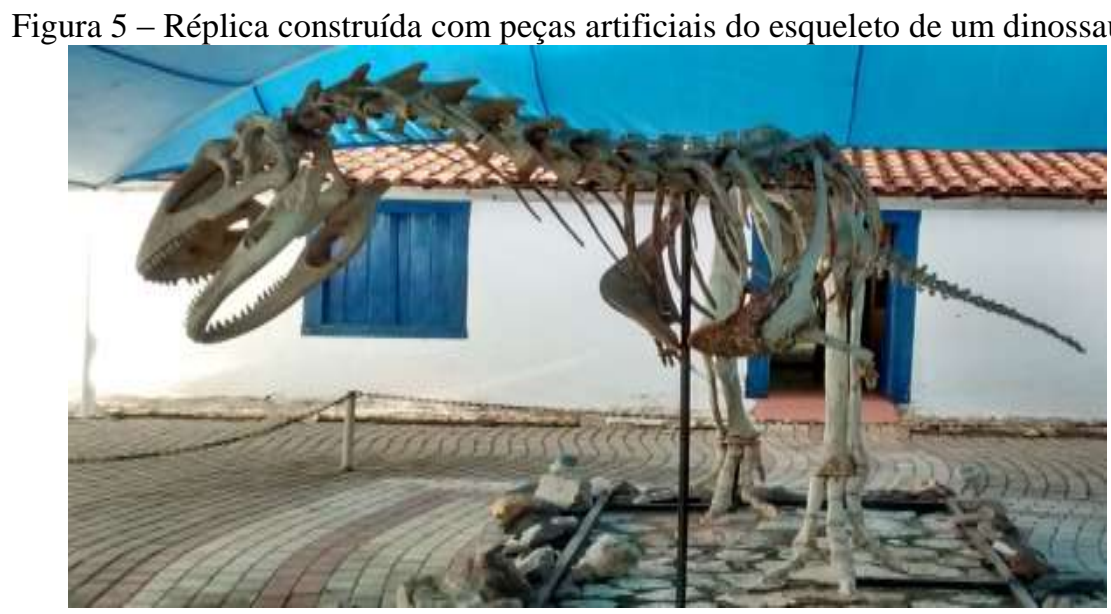

Foto: Acervo dos autores.

Há também, peças de esqueletos de outros animais, como as de um tatu e preguiça gigantes, também estão expostos no museu e representam a mesofauna pré-histórica do planeta e da região. Tais animais podem servir de objeto de estudo dos processos que envolvem as transformações do planeta, como extinções, corrente evolutiva de espécies, eras glaciais etc.

Além de peças pré-históricas, o museu possui uma área externa que permite abordar o estudo de espécies da mata ciliar do Rio Cuiabá (figura 6) e sua importância, por exemplo, para o solo e recursos hídricos. Em destaque na figura 6, um bambuzal, vegetação exótica utilizada 
para conservar os barrancos da erosão provocada pelas cheias do Rio Cuiabá, o que permite aplicar conceitos de botânica (Biologia) e erosão (Geografia).

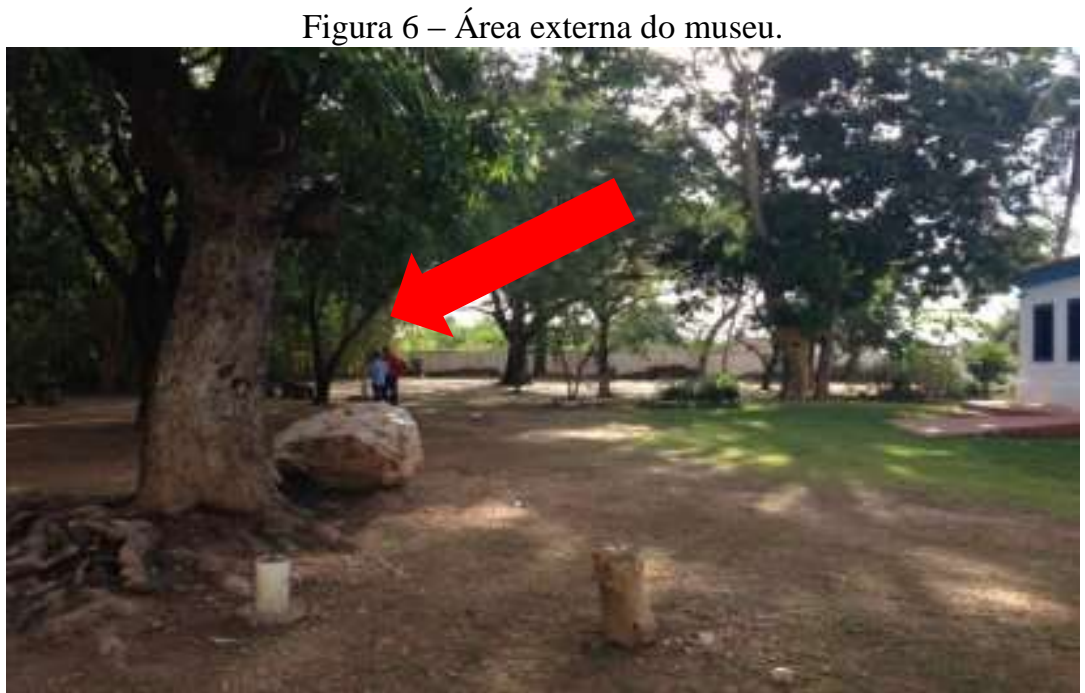

Foto: Acervo dos autores.

Uma problematização sobre conforto térmico também pode ser trabalhada nesse ambiente (figura 6), a partir de conceitos estudados em Biologia, Física, Matemática e História, pois, nesse local, é possível explorar as diferentes espécies vegetais, a área e as diferenças de temperatura do ambiente, bem como o tipo de construção do século XIX.

Essa área externa também traz uma intertextualidade por meio de uma obra de arte em argila (figura 7). Esta obra retrata uma mulher indígena trabalhando artesanalmente na fabricação de um vaso também de argila.

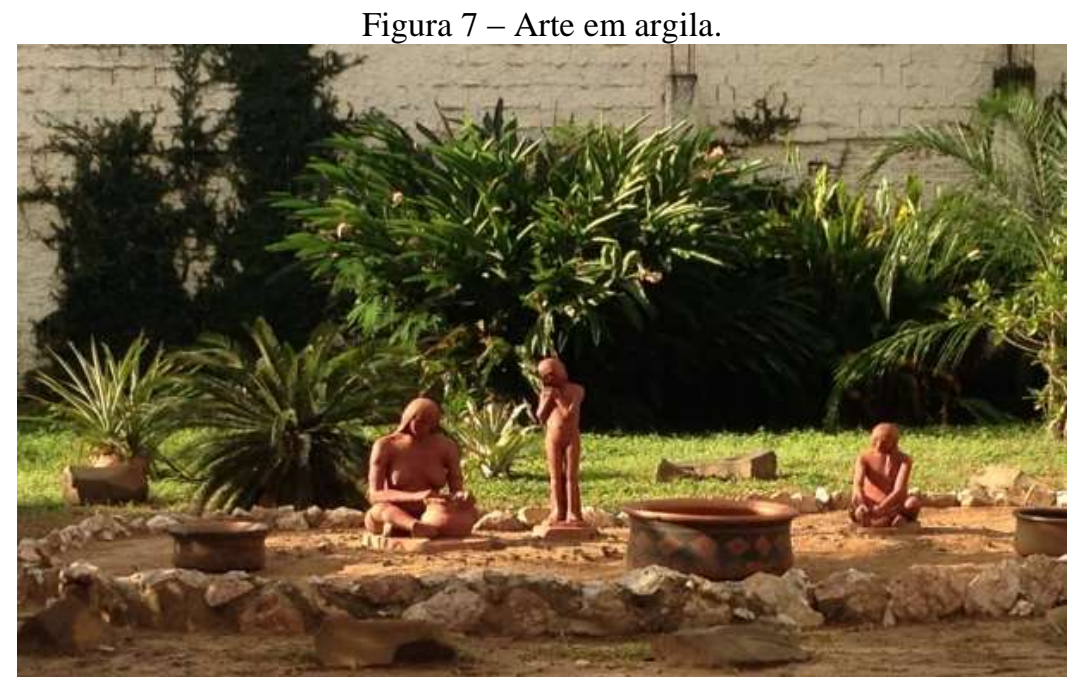

Foto: Acervo dos autores.

Com este tema, é possível abordar a herança cultural e a história dos artefatos desde a pré-história, problematizando a composição desse tipo de barro, entre outras coisas, 
questionando: O que o diferencia de outros tipos de solo? Quais substâncias o formam? Por que ele endurece tanto sem umidade? Por que a umidade 'desaparece'? Por que recipientes de barro utilizados para armazenar água a mantêm em temperatura menor que a do ambiente externo? Essas indagações podem ser trabalhadas envolvendo a Química e a Física, por exemplo.

O museu como espaço não formal de aprendizagem pode se constituir como uma metodologia significativa na ação do professor para o desenvolvimento de novas propostas de ensino, oportunizando aos alunos "uma formação mais ampla, visando a transformação no seu modo de ver o mundo e o saber científico" (SILVA et al., 2017), além de poder proporcionar como aula de campo, instrumentos para a desfragmentação do ensino positivista, como já apontado por Seniciato e Cavassan (2004).

\section{CONSIDERAÇÕES FINAIS}

Em uma perspectiva metodológica, destacamos dois pontos: a importância do professor se envolver com o ambiente a ser explorado para fins escolares, conhecendo suas potencialidades e limitações curriculares; e, do ponto de vista de formação docente, que deve ser constante, aprimorar práticas que possam melhorar a aprendizagem dos alunos por meio da pluralidade metodológica.

Desse modo, podemos afirmar que os espaços não formais podem ser utilizados para a prática educativa e, ainda, proporcionar aulas que envolvam múltiplas experiências para professores, alunos, monitores e demais pessoas ligadas a esses locais, desenvolvendo uma relação inter/multidisciplinar em se tratando de currículo, além de promover a interação da escola na presença de professores e alunos com a comunidade, oportunizando a reconstrução de significados.

A utilização de espaços não formais, em particular do museu de Pré-história aqui abordado, pode servir de mediadora para promover a cultura científica entre os alunos para além dos livros didáticos e do contexto escolar. Isto corrobora o desenvolvimento de aulas interdisciplinares e o rompimento com o tradicional ensino de ciências, totalmente desarticulado, verificado nas escolas. A interação do aluno com o espaço e a exposição que ali se encontra pode promover o seu protagonismo na ação de aprender, quer seja no campo das ciências naturais, humanas e/ou sociais.

Nesse contexto, o museu não pode ser visto apenas como um ambiente para visitação e entretenimento, ou ainda, um espaço de aprendizagem onde o aluno (ou visitante) seja apenas um espectador. Esse espaço deve ser explorado de tal forma que aguce a curiosidade em 
aprender além daquilo que está exposto, desencadeando discussões que ultrapassem a informação constante no livro didático ou no próprio museu.

Na utilização de espaços não formais nos processos educativos, destacamos que não só o museu pode ser usado para esse fim, mas também praças, parques, quintais, entre outros.

As questões aqui levantadas nos trazem a reflexão de que precisamos conhecer os fenômenos em sua amplitude para entender como as áreas de conhecimento se inter-relacionam, uma vez que foram criadas com o passar do tempo e, de certa maneira, o conhecimento foi se fragmentando em contextos positivistas, formando especialidades. Como consequência, o ensino também foi fragmentado, resultando em distorções científicas e, muitas vezes, na redução do interesse dos alunos por essas áreas.

Entendemos que espaços como o museu, certamente contribuem para o desenvolvimento cultural científico dos estudantes, configurando-se como espaços importantes para a contextualização de assuntos pertinentes ao ensino de ciências, bem como, associado a aspectos inerentes as ciências sociais e humanas. Não podemos desvincular que o desenvolvimento científico e o ensino de ciências são constructos do homem que vêm ocorrendo em diversas conjunturas históricas e sociais.

\section{REFERÊNCIAS}

ALMEIDA, E. R.; SILVA, M. S. V. Uma abordagem reflexiva sobre a realização do trabalho prático de campo como instrumento da construção do conhecimento. Ponta Grossa, 07 a 09 de out. 2010. Disponível em:

<http://www.sinect.com.br/anais2010/artigos/EB/199.pdf>. Acesso em 05 de mai. 2018.

CAZELLI, S.; QUEIROZ, G.; ALVES, F.; FALCÃO, D.; VALENTE, M. E.; GOUVEA, G.; COLINVAUX, D. Tendência pedagógicas das exposições de um museu de ciência. In. II ENCONTRO NACIONAL DE PESQUISA EM EDUCAÇÃO EM CIÊNCIAS (SP), 01 a 04 de set. 1999, Valinhos. Atas...São Paulo: ABRAPEC, 1999.

CAZELLI, S., MARANDINO, M., STUDART, D. Educação e Comunicação em Museus de Ciências: aspectos históricos, pesquisa e prática. In: Educação e Museu: a construção social do caráter educativo dos museus de ciências. Rio de Janeiro: FAPERJ, Editora Access, 2003.

CHASSOT, Á. I. Alfabetização científica: uma possibilidade para a inclusão social. Revista Brasileira de Educação. n. 22, jan/fev/mar/abr. p. 89-100, 2003.

CHASSOT, Á. I. Das disciplinas à indisciplina. Curitiba: Appris, 2016.

DOURADO, L. Concepções e práticas dos professores de Ciências Naturais relativas à implementação integrada do trabalho laboratorial e do trabalho de campo. Revista

Electrónica de Enseñanza de las Ciencias, v. 5, n. 1, p.192-212, 2006 a. 
DOURADO, L. O trabalho de campo na formação inicial de professores de biologia e geologia: opinião dos estudantes sobre as práticas realizadas. 2006b. Disponível em: $<$ http://enciga.org/files/boletins/61/o_trabalho_de_campo_na_formacao_professores.pdf $>$. Acesso em 05 de maio. 2018.

FAZENDA, I. C. A. Interdisciplinaridade: história, teoria e pesquisa. 15. ed. Campinas: Papirus, 2008.

FIGUEROA, A. M. S.; MARANDINO, M. A transposição museográfica e os objetos de exposições: as células nos museus de ciências. In: V ENEBIO e II EREBIO REGIONAL 1. 2014, Vitória, Revista da SBEnBio, n. 07, out. 2014.

GADOTTI, M. A questão da educação formal/não-formal. In: Institut International des droits de l'enfant (IDE), Suisse, 2005.

GOUVÊA, G.; MARANDINO, M.; LEAL, M. C. Educação e Museu: a construção social do caráter educativo dos Museus de Ciência. Rio de Janeiro: Ed. Access, 2003.

JACOBUCCI, D. F. C. Contribuições dos espaços não-formais de educação para a formação da cultura científica. Revista em Extensão, v. 7, p. 55-66, 2008.

MARANDINO, M. O Conhecimento Biológico nas Exposições de Museus de Ciências: análise do processo de construção do discurso expositivo. 2001. Tese (Doutorado em Educação). Faculdade de Educação, Universidade de São Paulo. 2001.

MARANDINO, M.: A pesquisa educacional e a produção de saberes nos museus de ciência. História, Ciências, Saúde - Manguinhos, v. 12 (suplemento), p. 161-81, 2005.

MARANDINO, M. As Perspectivas da Pesquisa Educacional em Museus de Ciências. In: SANTOS, F. M. T. dos; GREGA, I. M. (Orgs). A Pesquisa em Ensino de Ciências no Brasil e suas Metodologias. 2 ed. rev. Ijuí: Unijuí, p. 89-122, 2011.

MARTINS, L. C. A relação museu/escola: teoria e prática educacionais nas visitas escolares ao museu de zoologia da USP. 2006. 245 f. Dissertação (Mestrado em Educação). Faculdade de Educação, Universidade de São Paulo, São Paulo. 2006.

MINAYO, M. C. S. Ciência, Técnica e arte: O desafio da Pesquisa Social. In MINAYO, M.C.S (Org.). Pesquisa Social: Teoria, Método e Criatividade. Petrópolis: Vozes, 1994.

MUELleR, E. R. Educação do Campo na Amazônia Legal de Mato Grosso: o perfil do estudante egresso em relação à aprendizagem de química. 2012. 102 p. Dissertação

(Mestrado). Universidade Federal de Mato Grosso, Cuiabá. 2012.

OVIGLI, D. F. B. Prática de Ensino de Ciências: o museu como espaço formativo. Revista Ensaio, v. 13, n. 03, p. 133-149, 2011.

QUEIROZ, R. M.; TEIXEIRA, H. B.; VELOSO, A. S.; TERÁN, A. F.; QUEIROZ, A. G. A caracterização dos espaços não formais de educação científica para o ensino de ciências.

Revista Amazônica de Ensino de Ciências (Areté), v. 4, n. 7, p. 12-33, 2011. 
SABBATINI, M. Museus e centros de ciência virtuais: uma nova fronteira para a cultura científica. Revista Comciência, n. 45, p. 1-6, 2003.

SENICIATO, T.; CAVASSAN, O. Aulas de campo em ambientes naturais e aprendizagem em ciências: um estudo com alunos do ensino fundamental. Ciência \& Educação, v. 10, n. 1, p. 133-147, 2004.

SILVA, M. L.; TROIAN, T. V. S. P.; NETO, G. G.; HARDOIM, E. L. Do morro da caixa d'água velha ao mercado do porto: utilizando pontos turísticos de Cuiabá-MT como espaços não formais para o ensino de ciências e matemática. Revista Prática Docente, v. 2, n. 2, p. 292-303, 2017.

TEMPESTA, A. M.; GOMES, L. C. Contribuições de um museu de ciências para a formação docente em física. Investigações em Ensino de Ciências, v. 22 (1), pp. 78-102, 2017.

VIEIRA, V.; BIANCONI, M. L.; DIAS, M. Espaços não-formais de ensino e o currículo de ciências. Revista Ciência e Cultura, v. 57, n. 4, p. 21-23, 2005.

VYGOTSKY, L. S. A formação social da mente: o desenvolvimento dos processos psicológicos superiores. 6. ed. São Paulo: Martins Fontes, 1998.

Recebido em: 12 de abril de 2018.

Aprovado em: 20 de julho de 2018 . 